\title{
Awake king vision videolaryngoscope in a patient with nasopharyngeal angiofibroma: an encouraging experience
}

\begin{abstract}
Recent guideline on difficult intubation has included video laryngoscope as an initial approach for intubation. A young patient posted for nasophryngeal angiofibroma where even mask ventilation was difficult due to stuffiness of the nose. Moreover angiofibroma had penetrated the hard palate and was hanging into the posterior pharyngeal wall. Also the nasal bridge of the patient was broadened and there was a diffuse swelling especially over the left maxillary area.In such a situation paralysing the patient could have lead to catastrophy. So an awake intubation using king vision video laryngoscope was planned. After proper preparation for awake intubation, glottis opening was visualzed using king vision video laryngoscope and then a bougie was introduced into the glottis opening over which endotracheal tube was rail roaded. Using this device was very easy to handle and visualization of the vocal cord on the monitor was panoramic
\end{abstract}

Keywords: awake, intubation, king vision, nasopharyngeal angiofibroma
Volume 5 Issue 5 - 2016

\author{
Qazi Ehsan Ali,' Syed Hussain Amir,', Shadab \\ Kamal, ${ }^{3}$ Abdul Quadir,' Krochi Pal ${ }^{3}$ \\ 'Professor, Department of Anaesthesiology, Jawaharlal Nehru \\ Medical College, Aligarh Muslim University Aligarh, India \\ ${ }^{2}$ Assistant Professor, Department of Anaesthesiology, Jawaharlal \\ Nehru Medical College, Aligarh Muslim University Aligarh, India \\ ${ }^{3}$ Resident, Department of Anaesthesiology, Jawaharlal Nehru \\ Medical College, Aligarh Muslim University Aligarh, India
}

Correspondence: Qazi Ehsan Ali, Professor, Department of Anaesthesiology, Jawaharlal Nehru Medical College, Aligarh Muslim University Aligarh, Aligarh, UP, India, Tel +91 7417701769, Fax +91 57I-2720030, Email qaziehsanali@gmail.com

Received: June 18, 2016 | Published: September 14,2016

\section{Introduction}

Video laryngoscope has been suggested as an initial approach to difficult intubation by the recent guideline given by American Society of Anaesthesiologist. ${ }^{1}$ Video laryngoscopes have high percentages of Cormack-Lehane grades 1 and 2 in patients with predicted difficult airways and high successful intubation rate. ${ }^{2}$ It is indicated for intubation in awake patient when there are suspected difficult conventional laryngoscopy and intubation or difficult bag and mask ventilation. ${ }^{3}$ Fiberoptic intubation is the safest device among the anaesthesiologists for awake intubation, ${ }^{4}$ though there is difficulty in obtaining required skills. There are various other videoassisted devices which are comparatively inexpensive, require lesser maintenance and are easier to acquire expertise over them. The King vision video laryngoscope (Kingsystems Noblesville, IN) is one such device among various other videolaryngoscope which seems to be effective tool for awake intubation. This is the first report of its kinds to perform an awake intubation with king vision videolaryngoscope in patient with nasopharyngeal angiofibroma with intracranial extension.

\section{Case report}

A 15 year old patient weighing $32 \mathrm{~kg}$ reported to the hospital with nasal obstruction and discharge and headache for 4 months. He was a snorer and had a vascular tumour on the palate that bled on taking oral food and even on touch rendering the patient anaemic too. He was admitted for excision of the tumour. In the preoperative assessment, patient had soft to firm mass present in the nasal cavity eroding the hard palate which was visible through the oral cavity and extending to nasopharynx (Figure 1). The nasal bridge of the patient was broadened and there was a diffuse swelling especially over the left maxillary area. Computer Tomography scan was suggestive of a large heterogeneous density destructive mass lesion $(70 \mathrm{mmx} 65 \mathrm{~mm})$ involving the nasal cavity and left maxillary sinus with intracranial extension and extension into the sphenoid sinus, nasopharynx and soft tissue of face on left side. Mass had a tendency to bleed on touch and several hemorrhagic areas were present on the mass and the tongue was coated due to bleeding of tumour. Mallampati grade was IV, so awake intubation was planned as paralyzing the patient was risky and difficult intubation was expected.

Psychological counselling and consent for awake intubation was done with all the procedure of intubation and the patient shifted to pre-operative room after taking consent from the father of the patient. Premedication was done by inj. glycopyrolate $0.2 \mathrm{mg}$ i.v, inj. dexamethasone $8 \mathrm{mg}$ iv, inj. midazolam 1.0mg i.v, inj fentanyl $60 \mathrm{mcg}$ intravenously given 20 minutes before shifting the patient to operating room. Patient was then shifted to operating room. Standard monitors were attached. Two drops of xylometazoline was administered in the right nostril, patient was nebulised with $4 \%$ lidocaine and posterior pharyngeal wall was sprayed with $10 \%$ lidocaine.Swab soaked with lignocaine and adrenaline was placed over the posterior aspect of tongue. Superior laryngeal nerve block was given to patient by injecting $1 \mathrm{ml}$ of $1 \%$ lidocaine after palpating greater cornua of hyoid bone. $3 \mathrm{ml}$ of $1 \%$ lidocaine was also injected into the trachea after confirmation of needle by air bubbles in trachea at cricothyroid membrane and patient was asked to cough to allow spread of lidocaine downward into the trachea.

Patient was pre-oxygenated for 3 minute and lignocaine $50 \mathrm{mg}$ was given intravenously to blunt sympathetic response. King Vision video laryngoscope with non-channelled blade (Figure 2) was inserted in the oral cavity and when the vocal cord and glottis was visualised, a gum elastic bougie was inserted through the mouth and the curved tip of the bougie advanced into the trachea under the video guidance on viewing display of the monitor of the device. The endotracheal tube (ETT) of internal diameter of size $6.0 \mathrm{~mm}$ was then rail roaded over the bougie and advanced into the trachea. Placement of ETT was then confirmed by auscultation and capnography. Pharyngeal packing was done to prevent aspiration and anaesthesia was maintained with vecuronium, nitrous oxide and Propofol. Surgeon was then allowed to proceed. 


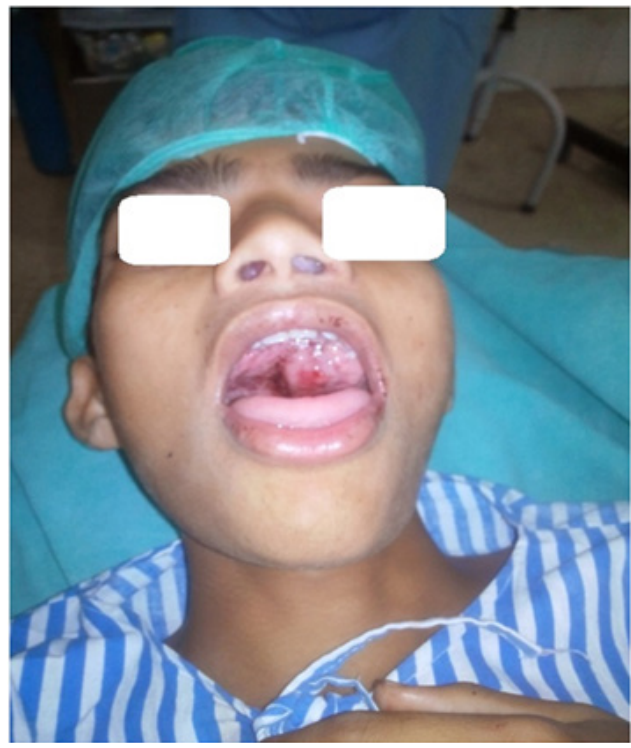

Figure I Patient with nasophryngeal angiofibroma extending into oral cavity.

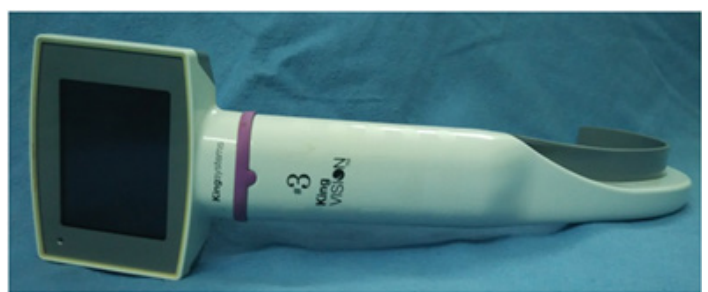

Figure 2 King Vision video laryngoscope with non-channelled blade.

\section{Discussion}

Difficult airway situation is one of the most challenging scenarios that an anaesthesiologist encounters in his profession. According to revised guideline of American Society of Anesthesiologists relative merits and feasibility of basic management plan to be assessed and awake intubation was better than intubating the patient after induction of general anaesthesia. This patient was considered for awake intubation because of the concern that patient was having higher grade of mallampati and with potential to hit the mass during laryngoscopy or advancement of the ETT, which might cause haemorrhage and worsening of visualization of the airway during laryngoscopy. Also there was chance of aspiration during laryngoscopy, hence paralysing the patient was risky.Revised guideline also suggested the use of video assisted laryngoscope as an initial approach in the management of difficult airway.

Awake intubation by fiberoptic bronchoscope is supposed to be the standard device among anaesthesiologist in patient with difficult conventional laryngoscopy and intubation and difficult bag and mask ventilation; since these devices are cheaper and have easy learning curve to expertise over them and the maintenance is also easier for them. According to the study done for required skills of fiberoptic intubation it was found that only $59 \%$ have required skills among anaesthesiologist of United States. ${ }^{5}$ The cost and maintenance is other concern for fiberoptic bronchoscope. With the emergence of a variety of other videolaryngoscopes which are easier to expertise, anaesthesiologist are preferring and trying it for endotracheal intubation in elective and emergency situations. So, though awake fiberoptic intubation is favourite but awake intubation by other videolaryngoscope are getting more popularity among anaesthesiologist. It has been seen that video laryngoscope are successful even after failed fiberoptic intubation. ${ }^{6}$

Although various video assisted laryngoscopes are tried and reported in the anaesthesia and emergency medicine literature; King vision videolaryngoscope is unique, two piece design, reusable monitor with disposable blade. The two piece are connected by just sliding over them. Though both channelled and non-channelled standard blades are available, we tried the non-channelled blade with gum elastic bougie in this case.

Videolaryngoscope have advantage over flexible fiberoptic bronchoscope having less laryngoscopy and intubation time because while performing fiberoptic bronchoscopy after visualization of glottis, tip of bronchoscope is advanced further inside the trachea till carina is visible then ETT is slided over it while in video laryngoscopy when the glottis is visible, ETT is passed under video guidance into the trachea. So fiberoptic bronchoscopy may take some extra time in passing the bronchoscope until carina is visible, and this time will accounts in the situation when anaesthesiologist is in hurry to intubate. Among the other videolaryngoscope king vision has few advantages in terms of its cost portability and clarity of the view. Although other video laryngoscope reported for difficult airway scenarios are GlideScope, ${ }^{7}$ McGrath video laryngoscope, ${ }^{8} \mathrm{C}$ MAC videolaryngoscope, ${ }^{9}$ Pentex airway scope, ${ }^{10}$ etcin the medicalliterature; among these, King vision videolaryngoscope is a newer, cheaper and portable device and seems to be an effective tool for managing awake intubation in difficult airway situations, and may be even more effective than fiberoptic bronchoscope.

\section{Conclusion}

King Vision Video laryngoscope is a simple and effective intubating device which can be used in difficult airway situations and may replace the need for fiberoptic bronchoscope where fiberoptic bronchoscope is not available.

\section{Acknowledgments}

None.

\section{Conflicts of interest}

The authors declare there is no conflict of interests.

\section{Funding}

None.

\section{References}

1. American Society of Anesthesiologists, Practice Guidelines for Management of the Difficult Airway; An Updated Report by the American Society of Anesthesiologists; Task Force on Management of the Difficult Airway; Anesthesiology. 2013;118:251-270.

2. Dotson M. Awake Video Laryngoscope Intubation:Case Report of a Patient With a Nasopharyngeal Mass. AANA Journal. 2012;80(5):347353.

3. American Society of Anesthesiologists Task Force on Management of the Difficult Airway. Practice guidelines for management of the difficult airway:an updated report by the American Society of Anesthesiologists Task Force on Management of the Difficult Airway. Anesthesiology. 2003;98(5):1269-1277.

4. Benumof JL. Management of the difficult adult airway. With special emphasis on awake tracheal intubation. Anesthesiology. 1991;75(6):1087-1110. 
5. Ezri T, Szmuk P, Warters RD, et al. Difficult airway practice patterns among anesthesiologists in the United States:have we made any progress? J Clin Anesth. 2003;15(6):418-422.

6. Sinofsky AH, Milo SP, Scher C. The awake Glidescope intubation: an additional alternative to the difficult intubation. Middle East $J$ Anesthesiol. 2010;20(5):743-746.

7. Doyle DJ. Awake intubation using the GlideScope laryngoscope:initial experience in four cases. Can J Anaesth. 2004;51(5):520-521.
8. Uslu B, Damgaard NR, Kristensen BB. McGrath videolaryngoscope for awake intubation in a patient with severe ankylosing spondylitis. $\mathrm{Br} J$ Anaesth. 2010;104(1):118-119.

9. Cavus E, Neumann T, Doerges V, et al. First clinical evaluation of the C-MAC D-blade videolaryngoscope during routine and difficult intubation. Anesth Analg. 2011;112(2):382-385.

10. Asai T, Liu EH, Matsumoto S, et al. Use of the Pentax-AWS in 293 patients with difficult airways. Anesthesiology. 2009;110(4):898-904. 